Supporting Information

\title{
Total Synthesis of Reblastatin
}

Iwona Wrona, Ana E. Garbada, Gwilherm Evano, James S. Panek*

Department of Chemistry and Center for Methodology and Library Development, Metcalf Center for Science and Engineering, Boston University, 590 Commonwealth Avenue, Boston, Massachusetts 02215

Selected Spectra 


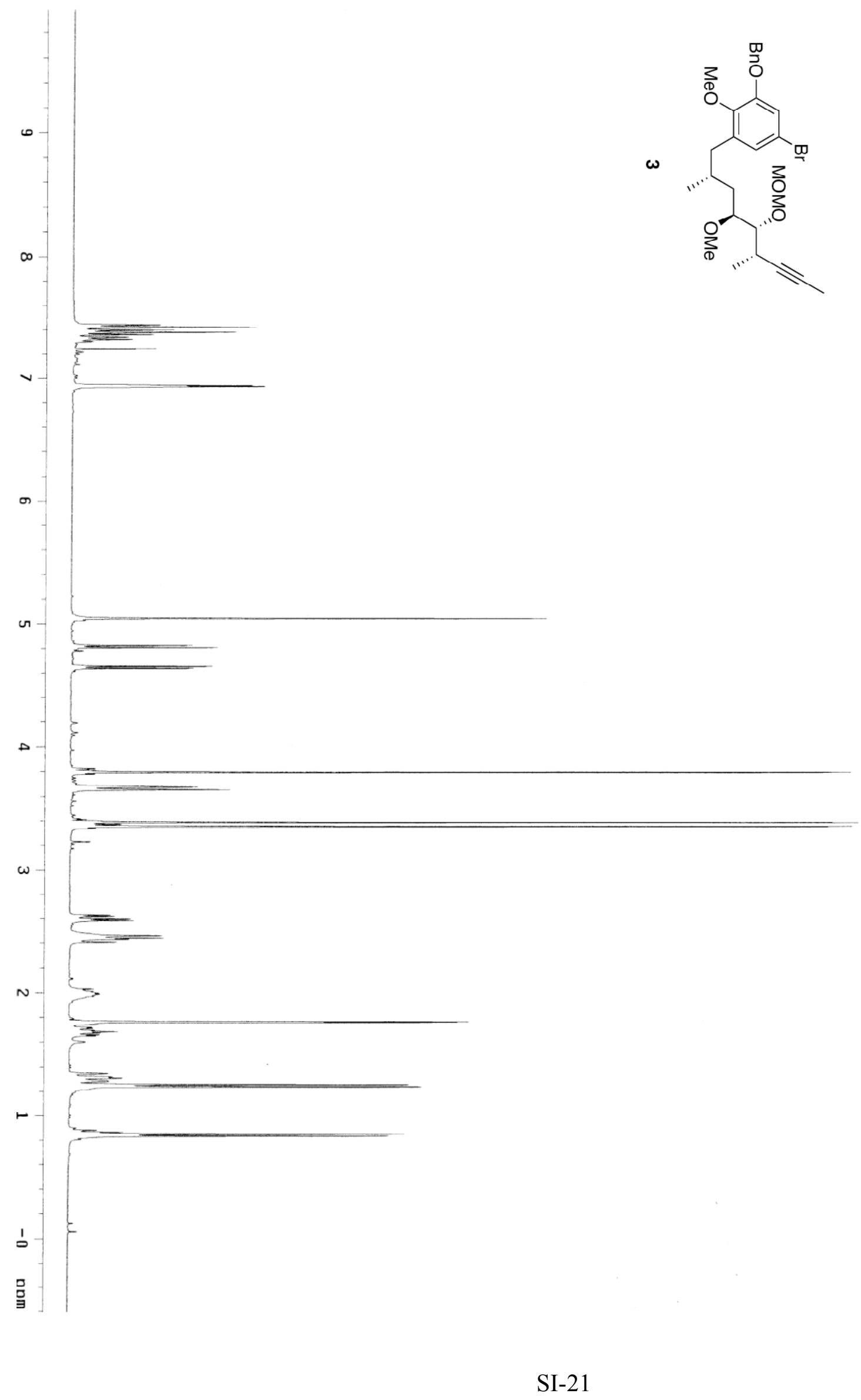



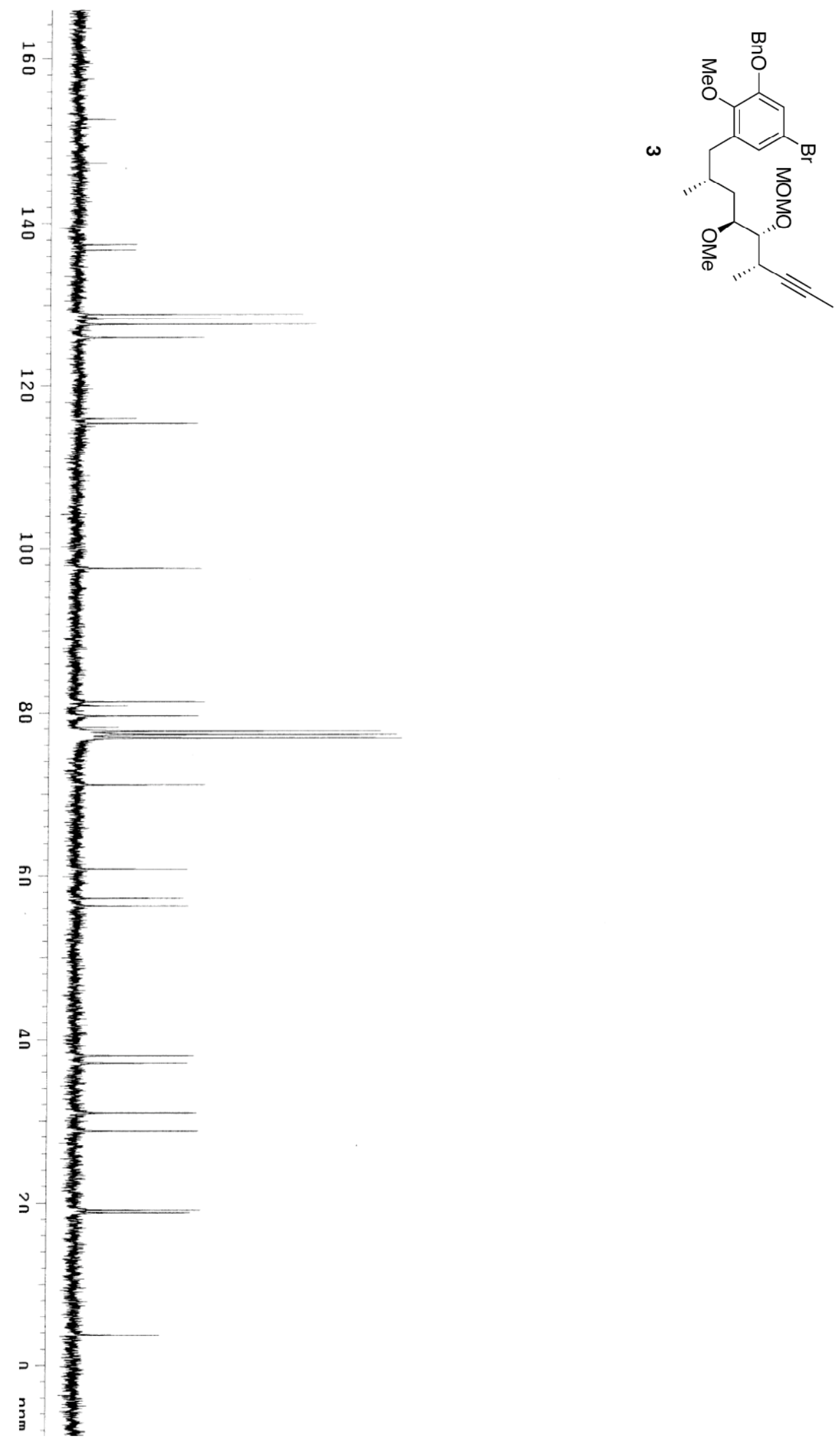

SI-22 


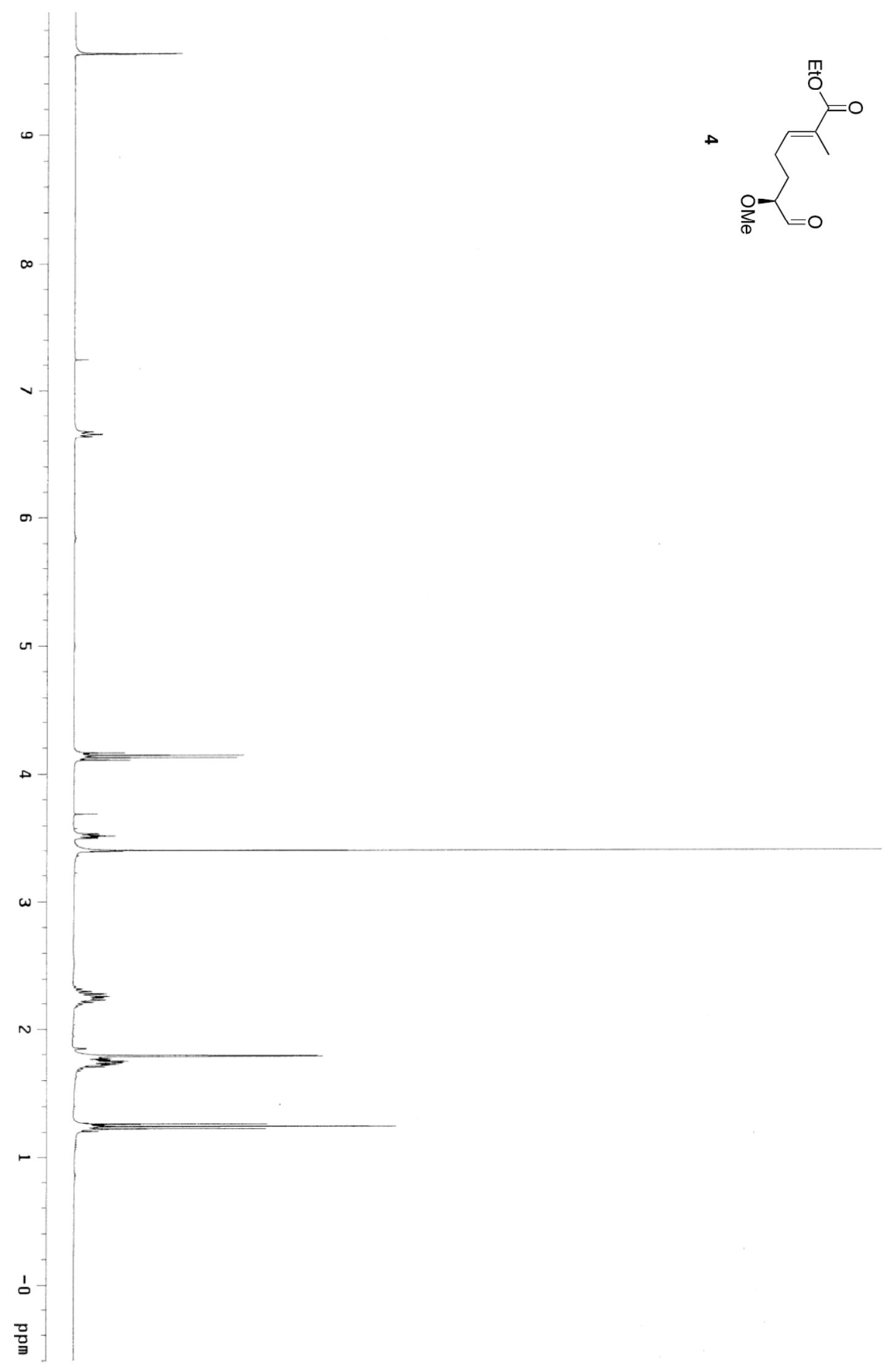

SI-23 


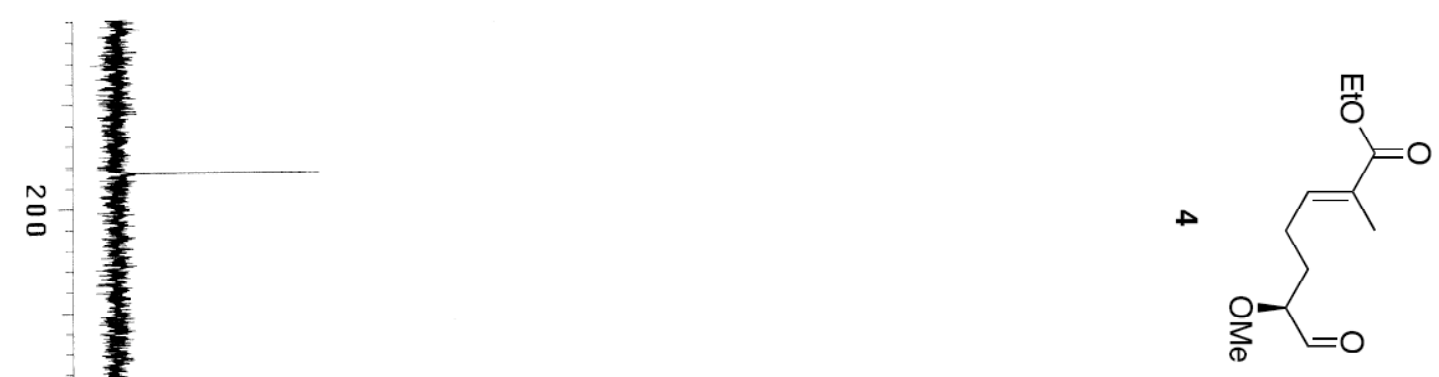

品

홍

点

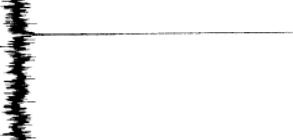

¿

N.

.

-

霋

옴

-

- 滖

- 章

a

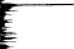

亲 


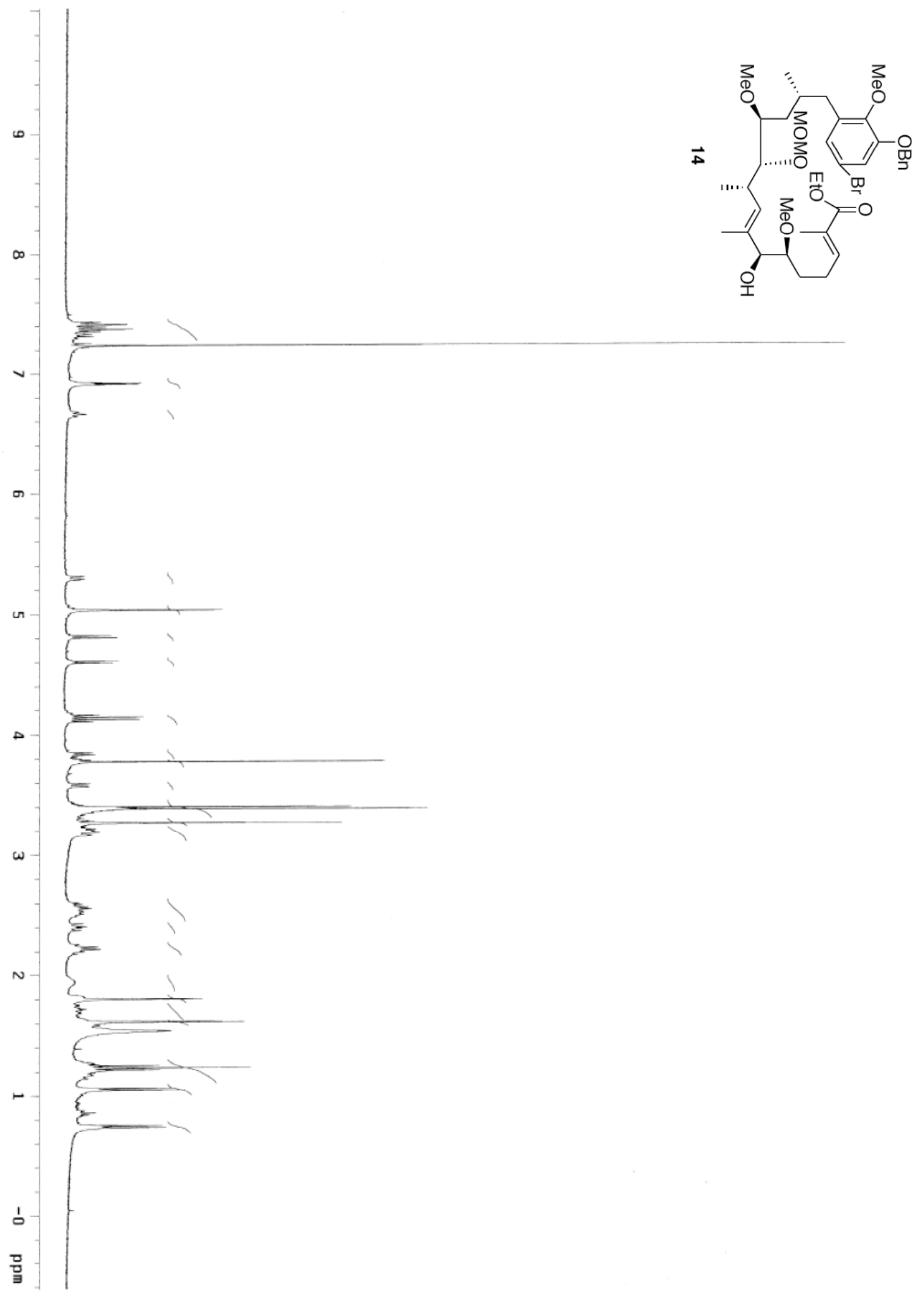

SI-25 


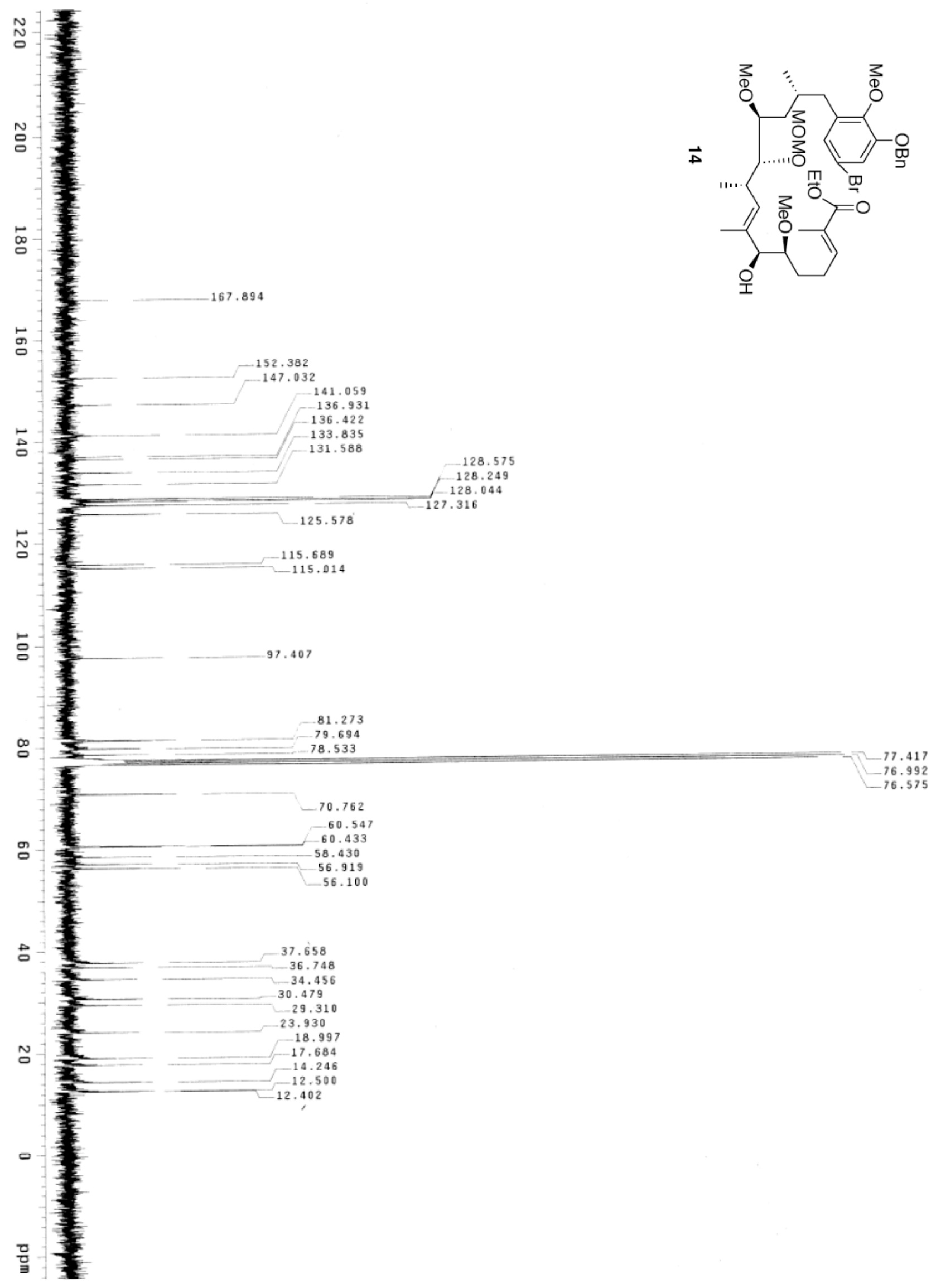




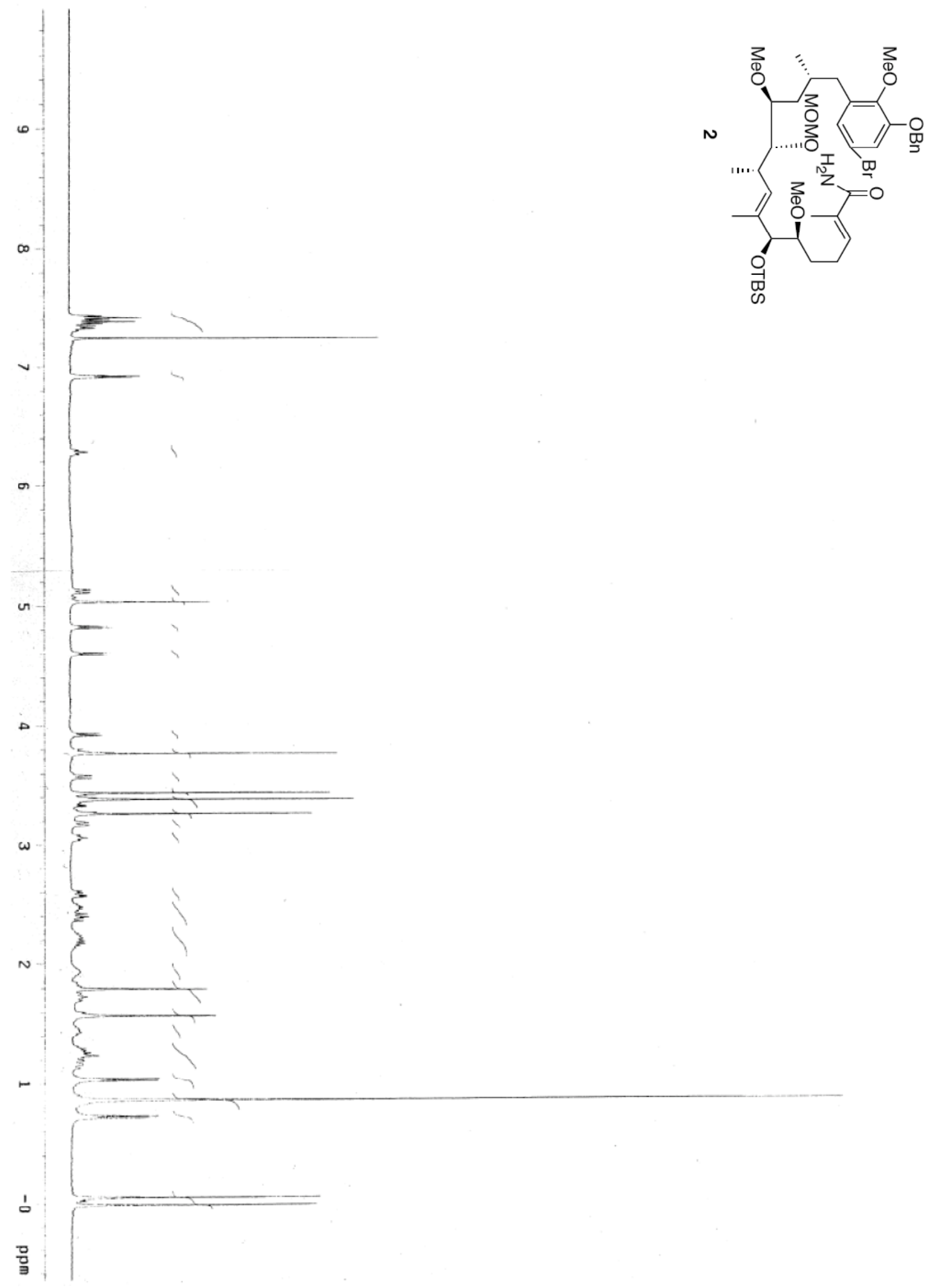




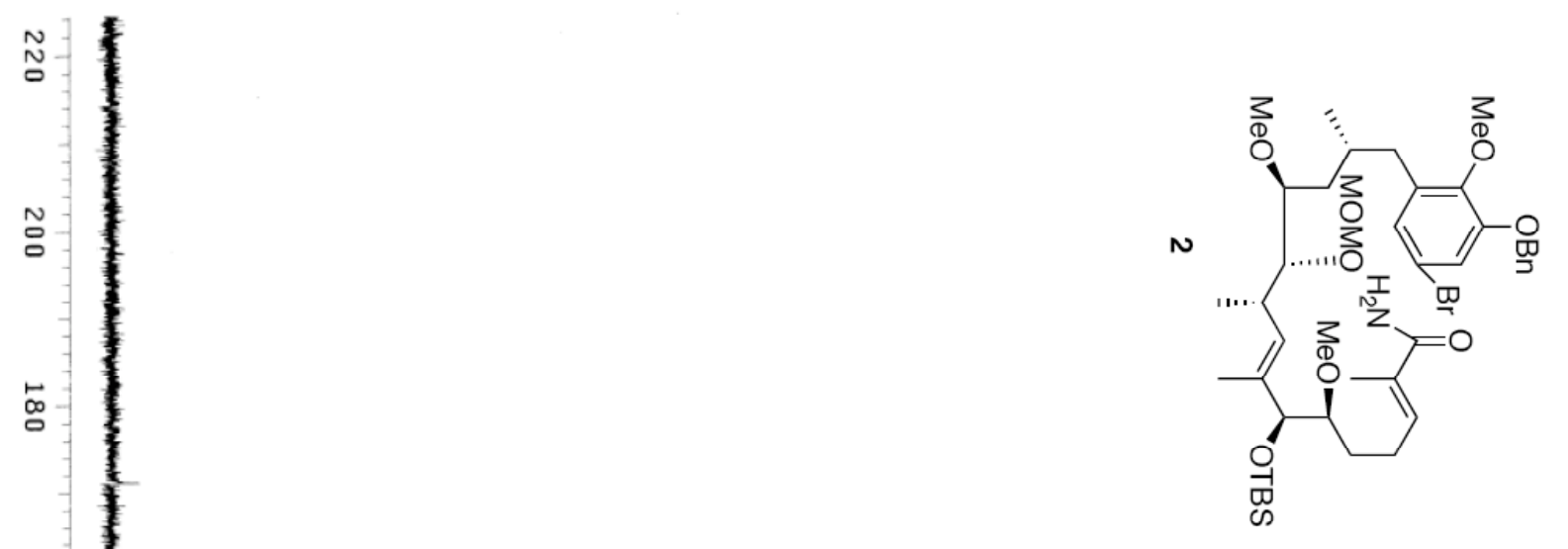

ต

宫

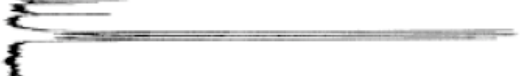

g

-

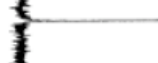

,

믐

:

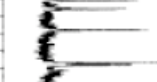

․

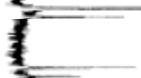

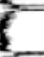

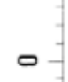

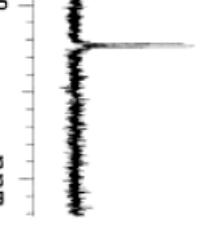

SI-28 


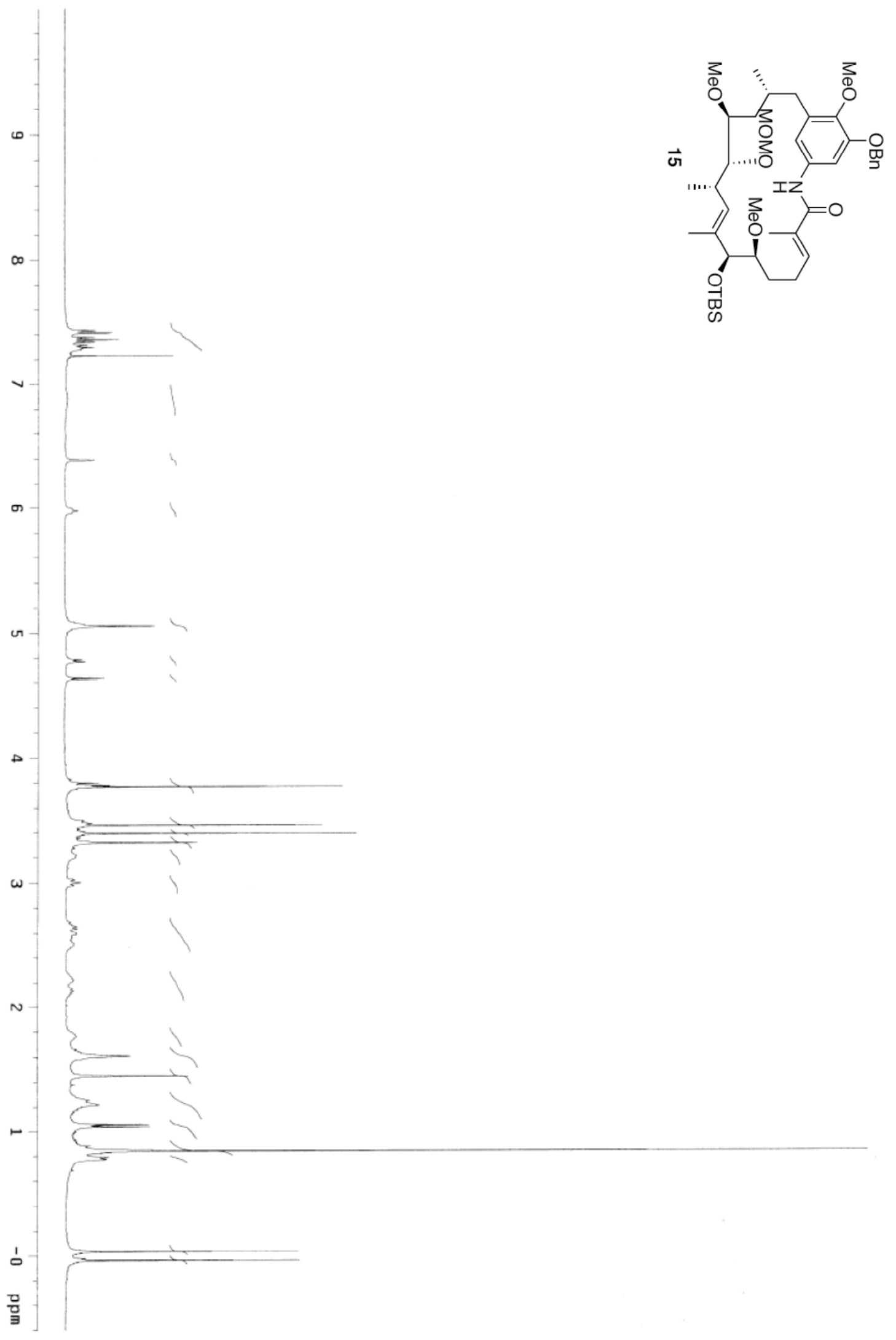

SI-29 


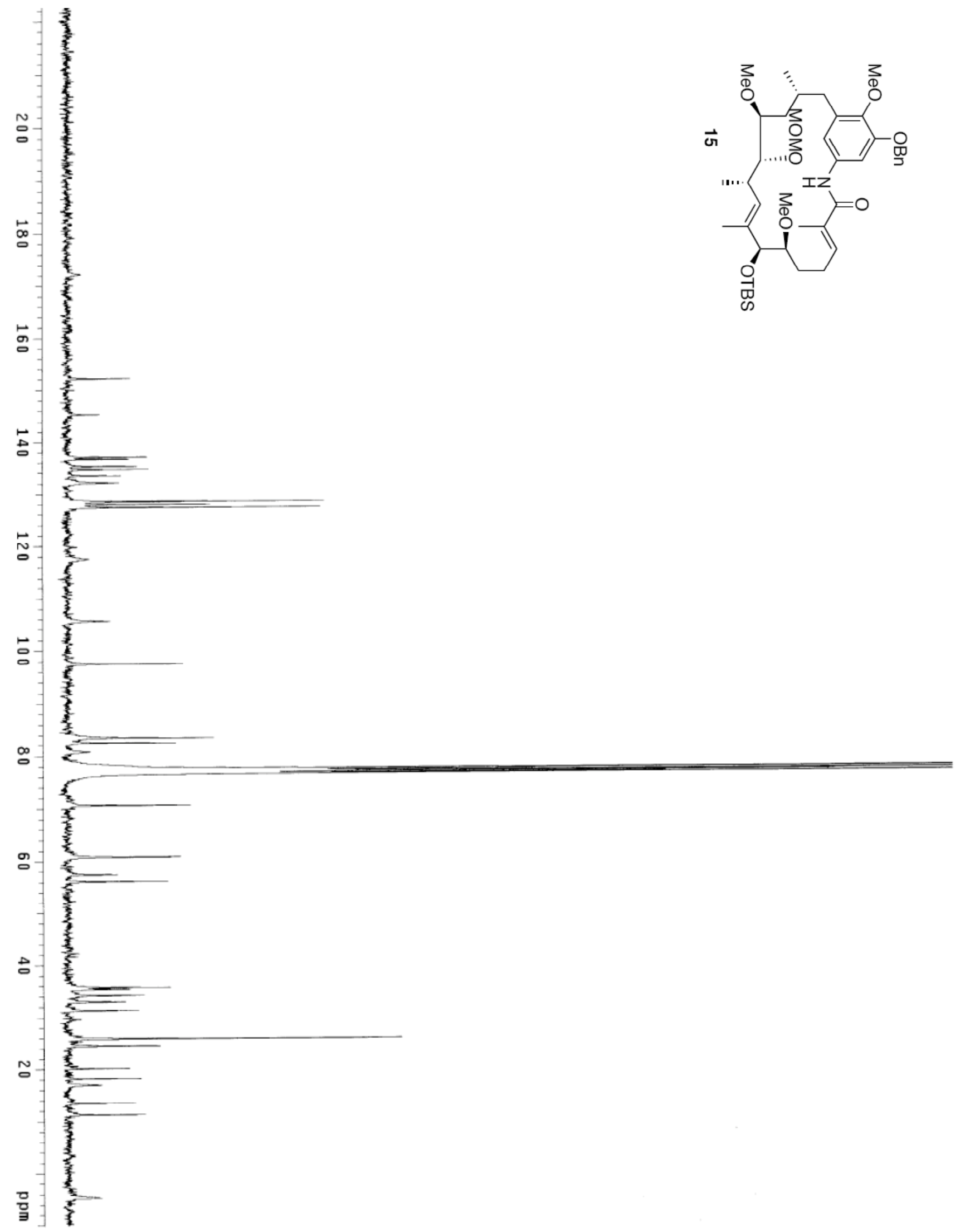

SI-30 


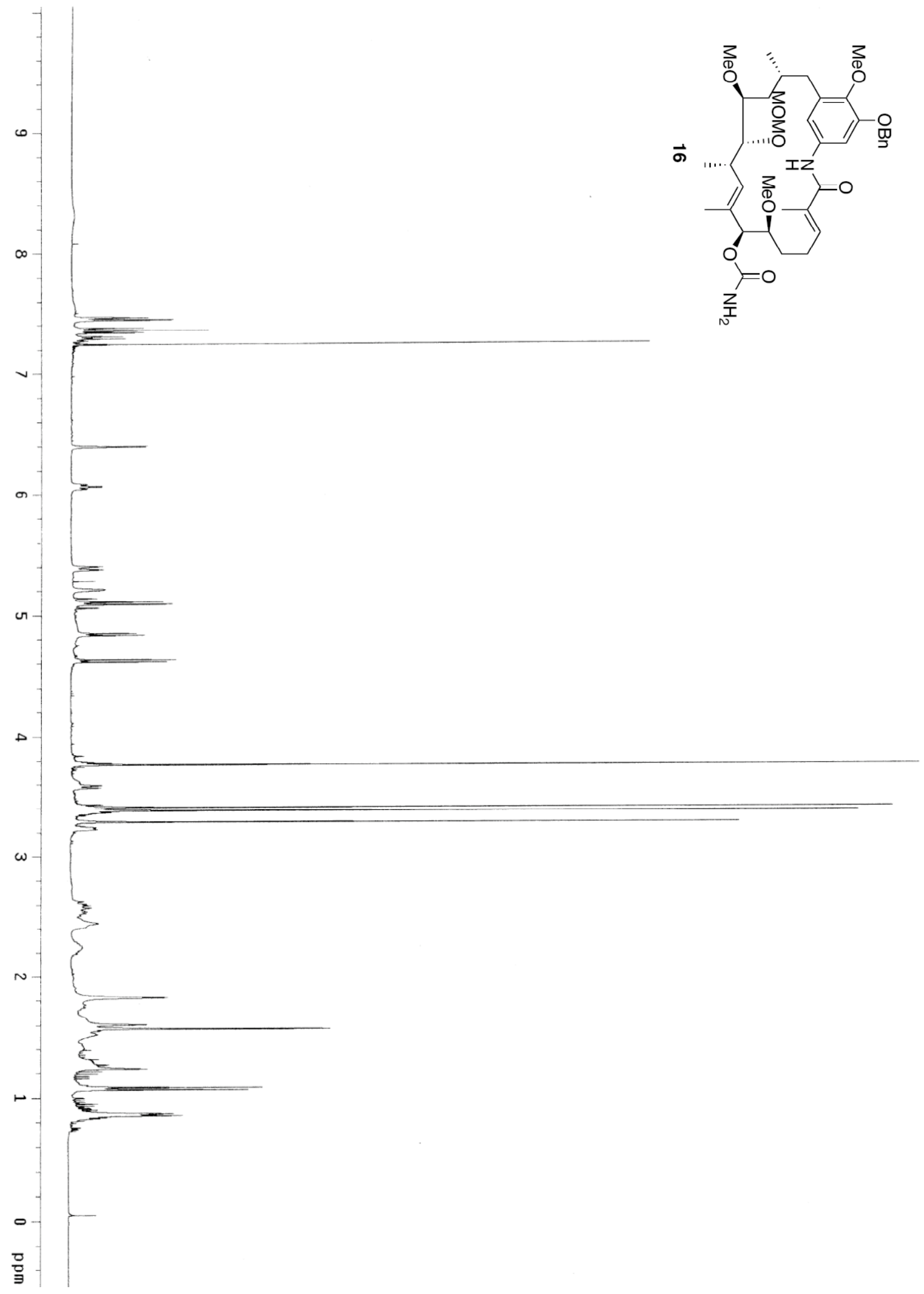

SI-31 

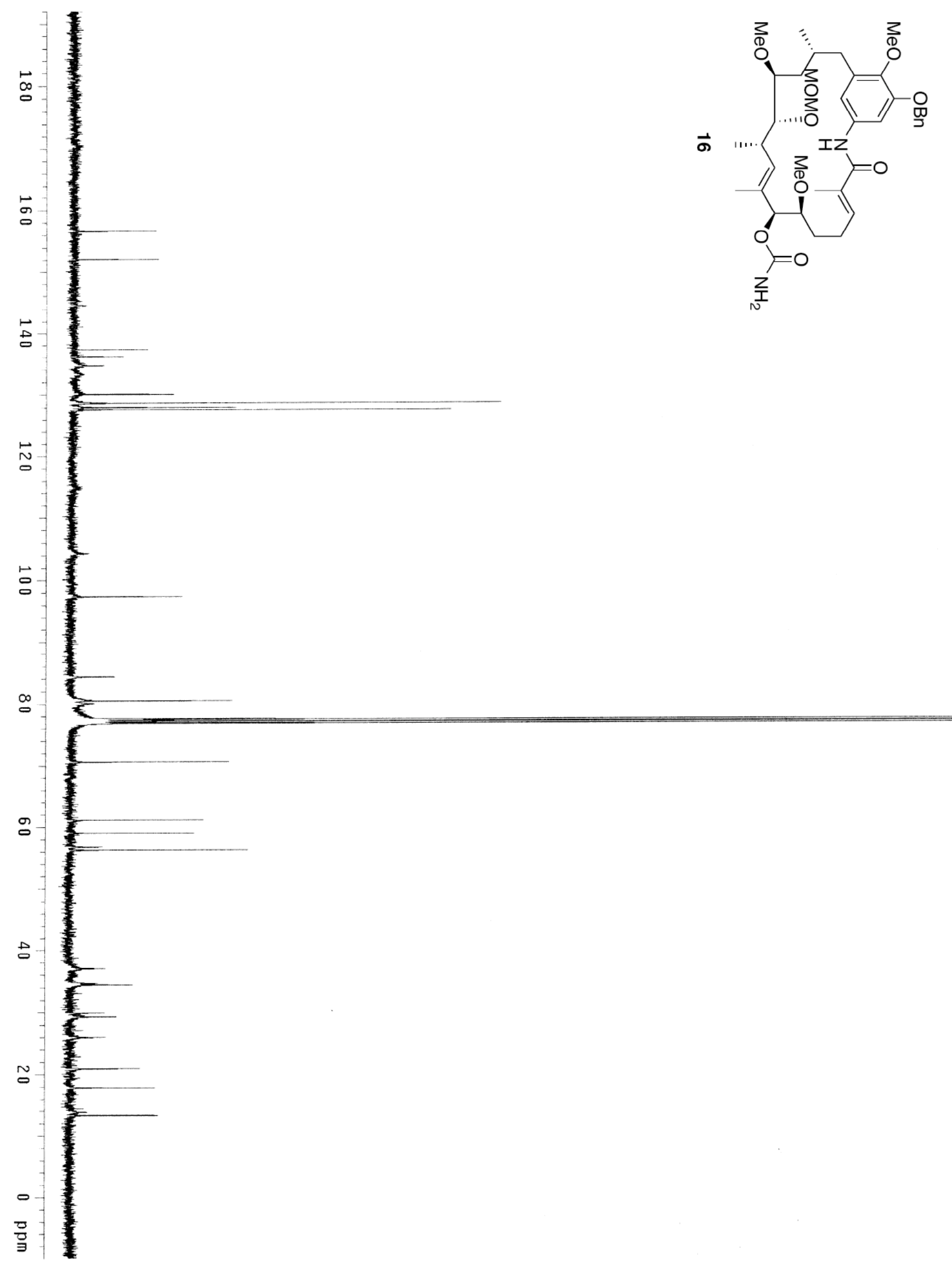


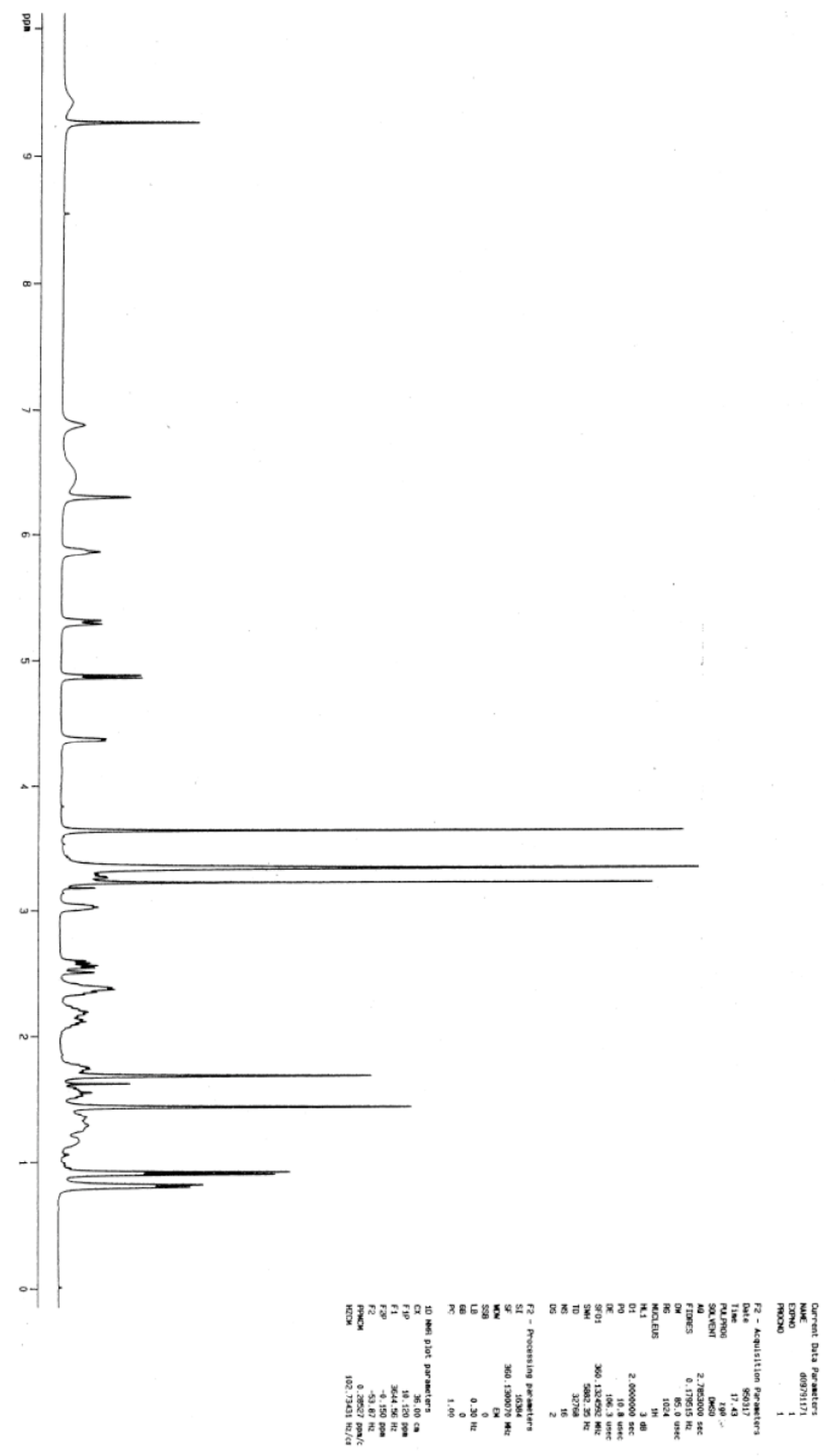

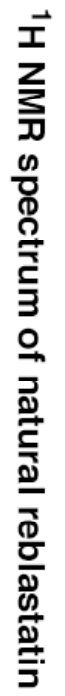

SI-33 


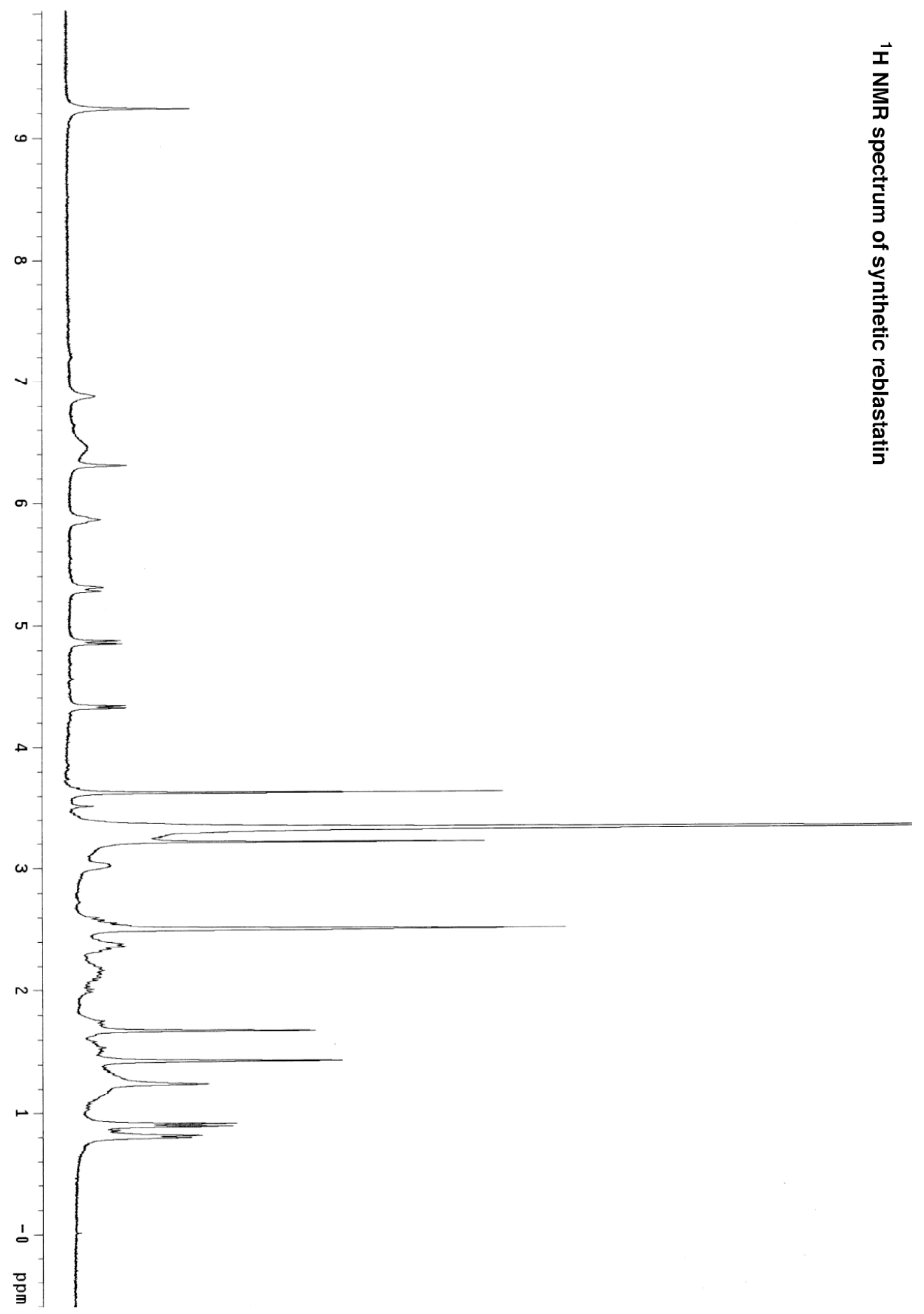

SI-34 


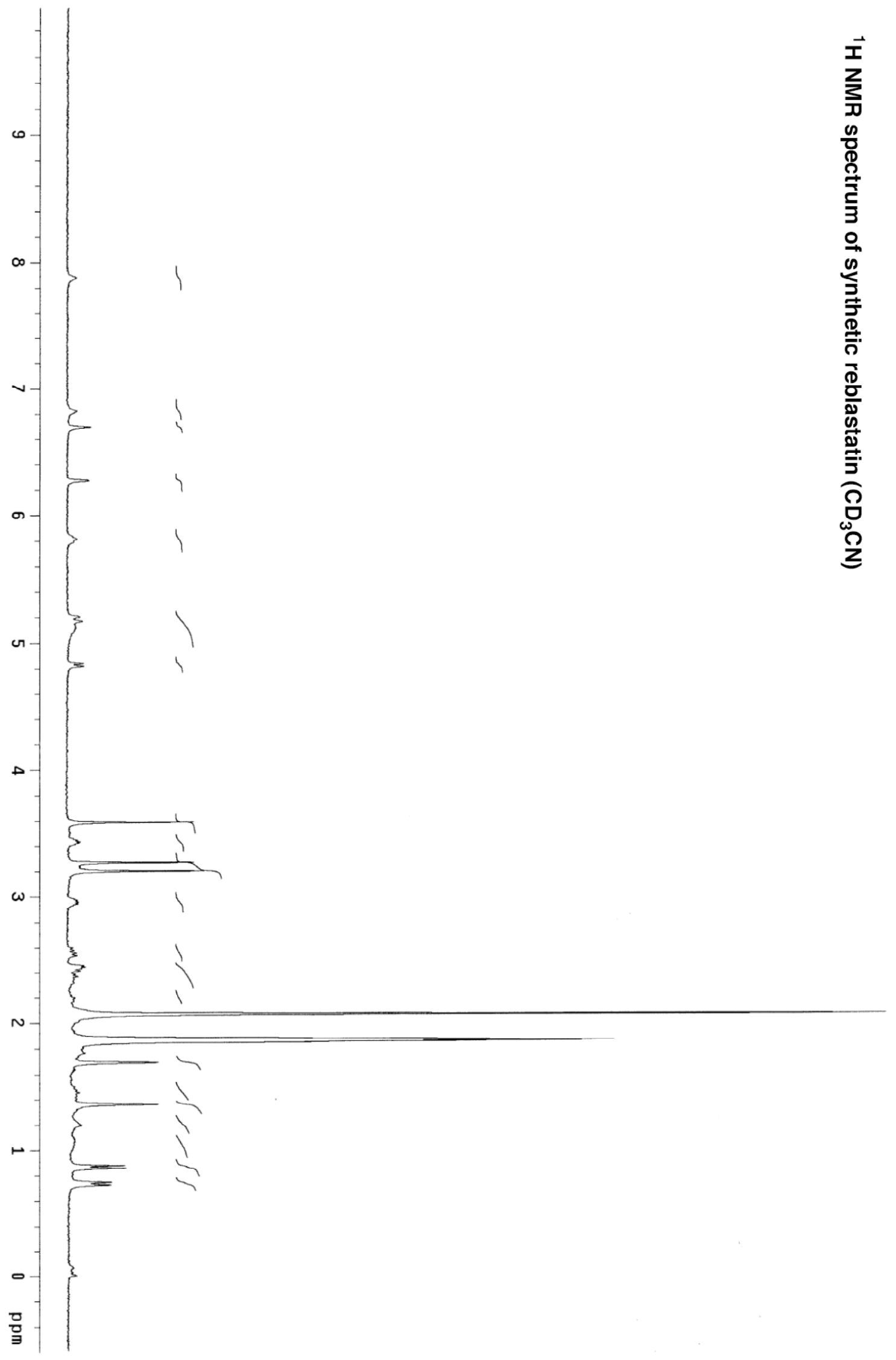




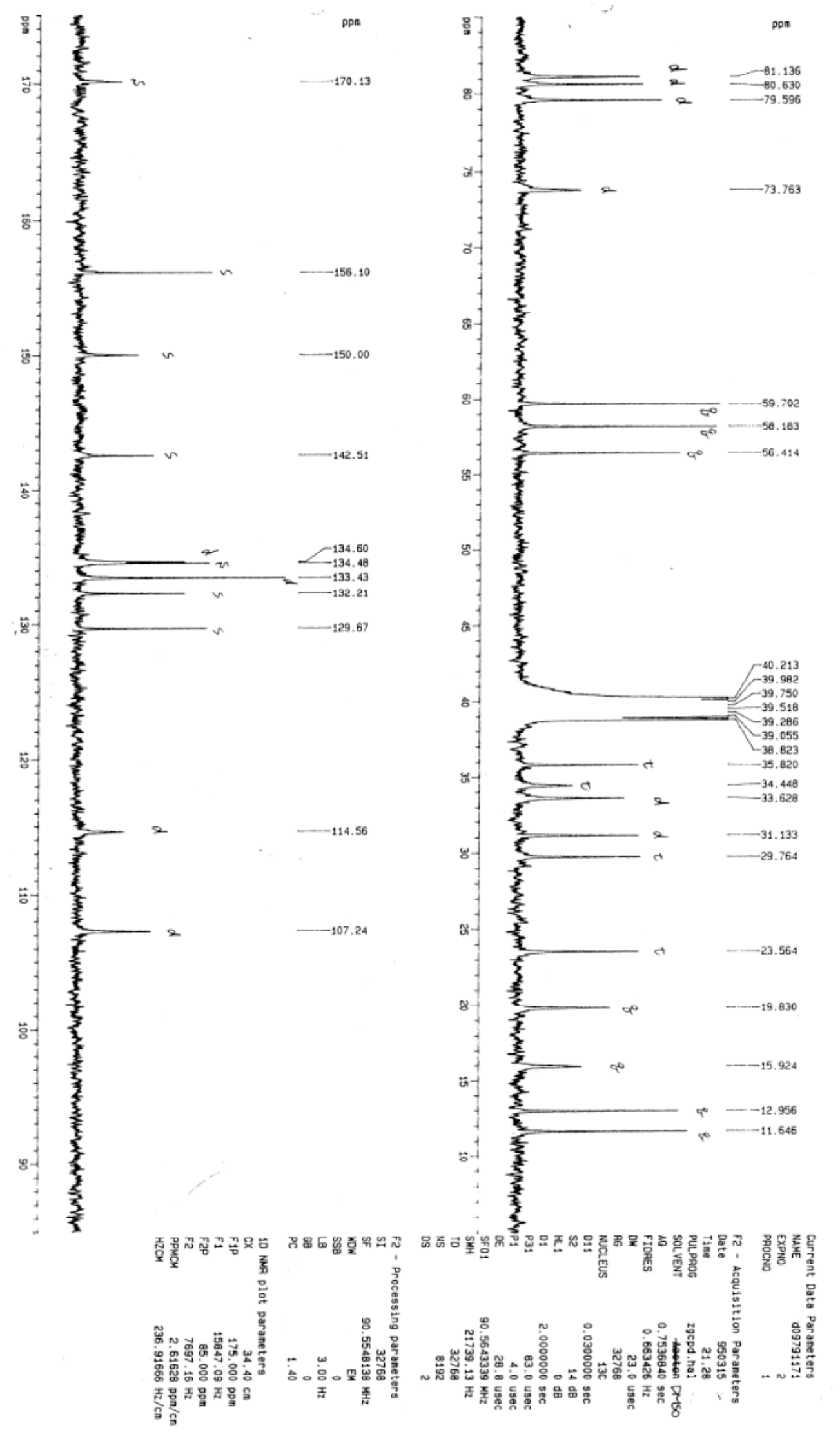

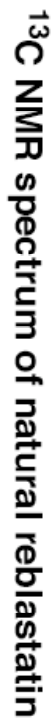




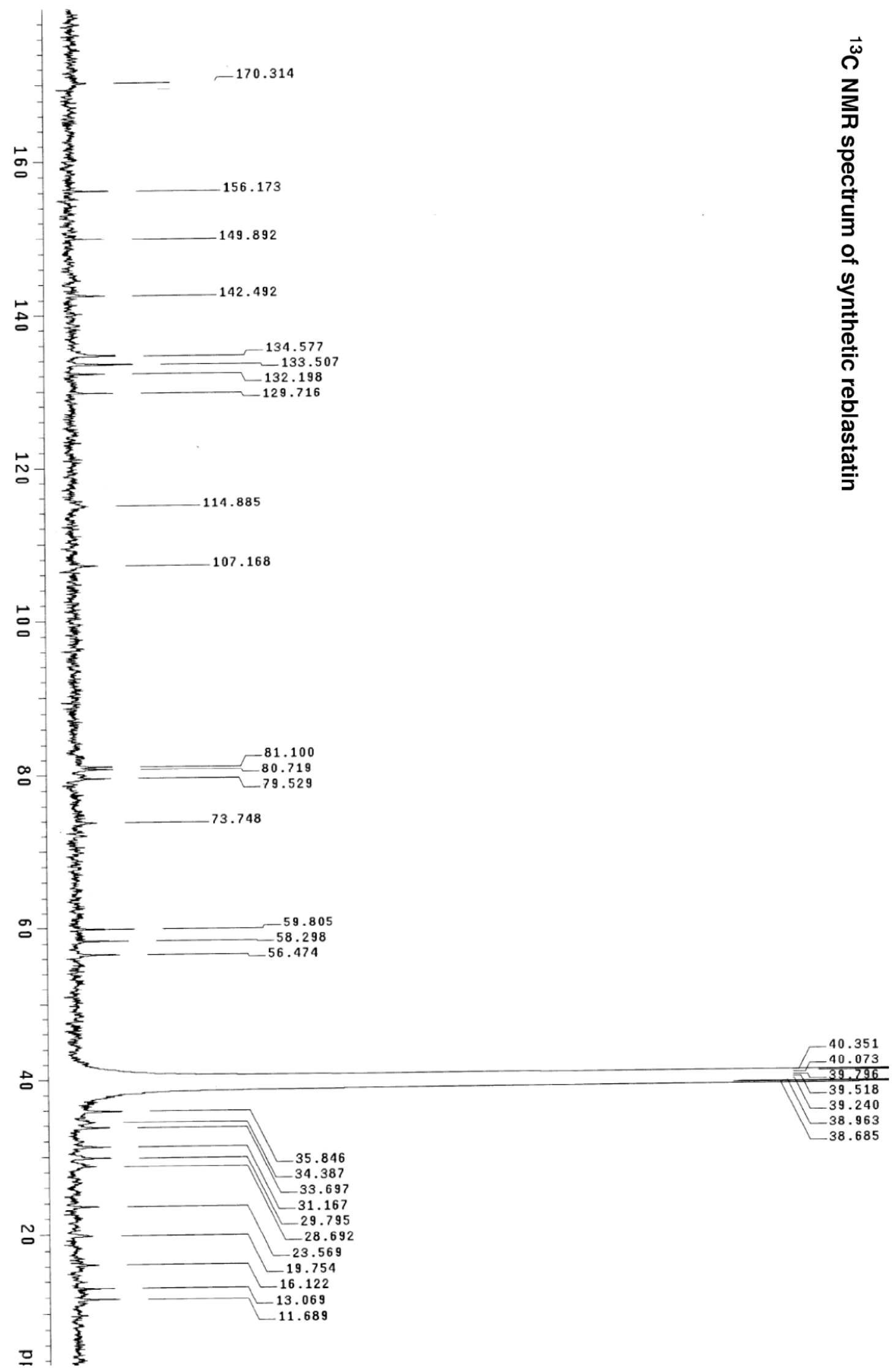

